8-1-2019

\title{
Prioritizing and targeting SBC investments to address adolescent pregnancy in USAID priority countries [4 pages]
}

Breakthrough RESEARCH

Follow this and additional works at: https://knowledgecommons.popcouncil.org/departments_sbsr-rh How does access to this work benefit you? Let us know!

\section{Recommended Citation}

Breakthrough RESEARCH. 2019. "Prioritizing and targeting social behavior change investments to address adolescent pregnancy in USAID priority countries," Programmatic Research Brief. Washington, DC: Population Council. [4-page brief] 


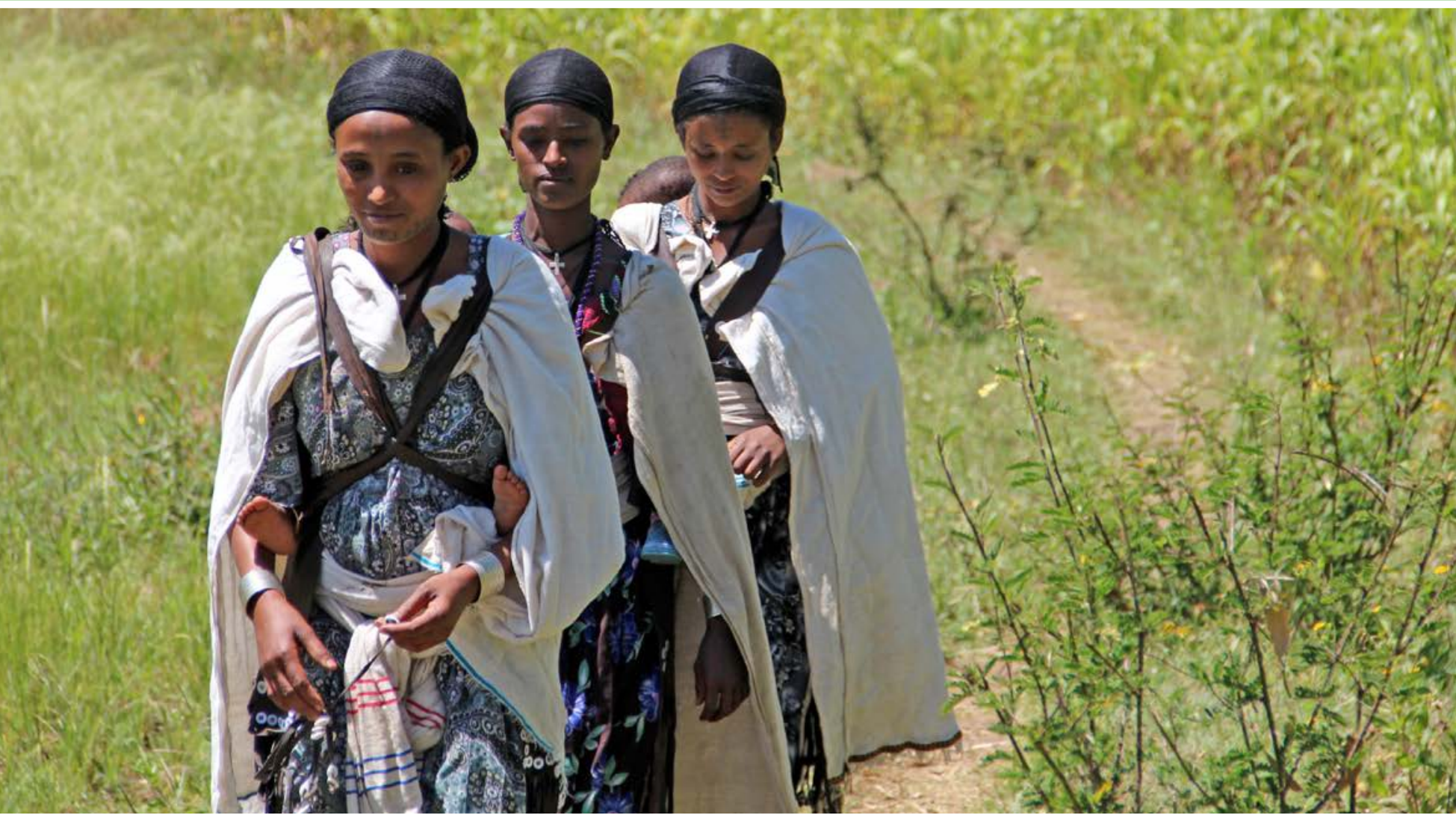

\section{Prioritizing and Targeting SBC Investments to} Address Adolescent Pregnancy in USAID Priority Countries

This document is intended for global and country-level decision-makers and family planning (FP)/reproductive health (RH) program implementers in USAID priority countries. It underscores the need for investments in adolescent and youth sexual and reproductive health (AYSRH) programming that include social behavior change (SBC) interventions, and illustrates a targeted approach for programming. It presents the scope and type of potential SBC investments for addressing pregnancy among unmarried and married adolescents.

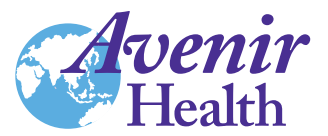

\section{KEY POINTS}

Early marriage is the predominant contributor to adolescent pregnancy.

Effective SBC interventions will be tailored for the unique circumstances of unmarried adolescent girls and adolescent brides and mothers.

A combination of factors related to adolescent childbearing should be considered to determine whether SBC investments should focus on addressing norms around early marriage, increasing demand for contraceptives, and/or reducing stigma around adolescent sexuality. 


\section{Background}

Globally, there are approximately 20 million pregnancies a year among 15-19 year olds in developing regions. ${ }^{1}$ Reducing pregnancy among adolescents ${ }^{2}$ is a key objective of international agreements on the health and rights of children and a priority of USAID Global Health investments. ${ }^{3}$

Likewise, providing youth access to FP/RH services is essential for reaching FP2020 goals and country commitments. Pregnancy presents many risks to adolescent girls and their children. Early childbearing is linked with higher maternal mortality and morbidity and increased risk of induced, mostly illegal and unsafe, abortions. ${ }^{4}$ It reduces girls' likelihood of completing their education or acquiring vocational skills, which has a negative impact on their socioeconomic standing; perpetuating poverty from one generation to another. Children born to adolescent mothers are more likely to experience adverse health consequences, such as low birth weight, preterm delivery, severe neonatal conditions, and early neonatal death. ${ }^{5}$ They are also more likely to have poorer educational, behavioral, and health outcomes throughout their lives, compared with children born to older mothers. ${ }^{6}$

\section{SBC interventions use tested}

communication principles and methods

tailored to audience needs to promote

healthy patterns of decision-making

and behavior. Learn more about SBC

interventions through the High Impact

Practices for Family Planning at www.

fphighimpactpractices.org.

Decision-makers often assume that most adolescent pregnancies are unintended and happen outside of marriage. While unintended pregnancy is a serious issue, decisionmakers may underestimate the social pressures and other complexities that can lead girls to seek early motherhood to prove fertility and establish an accepted role in society. ${ }^{7}$ SBC interventions recognize such complexities and use tested communication principles and methods are tailored to audience needs to promote healthy patterns of decision-making and behavior. Effective SBC interventions are grounded in behavioral theory and recognize that behavior change is more likely to occur in an enabling environment where effective protective factors are promoted and barriers removed. ${ }^{8}$ To achieve this, a multi-component approach is necessary, and at multiple levels of influence: at the individual level to facilitate adolescents' empowerment; at the relationship level to promote supportive relationships with partners, parents, and peers; at the community level to change social norms that enable adolescents to learn about their sexuality, access services, and challenge harmful practices; and at the societal level (policies, laws, and media campaigns) to create structural change that supports AYSRH. ${ }^{9}$

Targeting the right audiences with the right set of messages is essential for SBC, especially when promoting complicated behavior change, like pregnancy prevention, birth spacing, and modern contraceptive use. One method for targeting programming for adolescents is by marital status: in settings where early marriage is the norm, it is the predominant contributor to adolescent pregnancy. Thus, the FP/RH needs of girls who have never been married are different than the $\mathrm{FP} / \mathrm{RH}$ needs of girls who become brides and mothers during adolescence. Effective AYSRH interventions must consider and tailor their programming for the unique circumstances of girls in each situation. ${ }^{10}$

\section{A Closer Look}

In Figure 1 on the next page, the further to the right a country sits, the higher the levels of adolescent childbearing. Along this axis, adolescent childbearing ranges from $7 \%$ in Rwanda to $39 \%$ in Mali. The higher up a country is situated, the greater the percentage of adolescent pregnancies that occur after marriage. The share of pregnancies that occur after marriage ranges from $23 \%$ in Rwanda (where premarital pregnancies are higher) to $88 \%$ in India (where premarital pregnancies are lower).

\section{SBC Investment Options}

There is wide variation among countries and the type of SBC programmatic investments needed to reach adolescents with effective SBC interventions. The figure suggests that decision-makers should consider the two dimensions together (when making programmatic decisions). While decision-makers should strive to lower rates of adolescent pregnancy and childbearing, it is unlikely that levels for either will ever reach zero.

1 In countries where most pregnancies happen after marriage, for example India, Ethiopia, Nepal, and Yemen, SBC investments should focus on delaying early marriage, addressing norms around early marriage, childbearing soon after marriage, and birth spacing. Other effective investments include promoting respectful relationships, and teaching husbands to be supportive partners. ${ }^{11}$ 


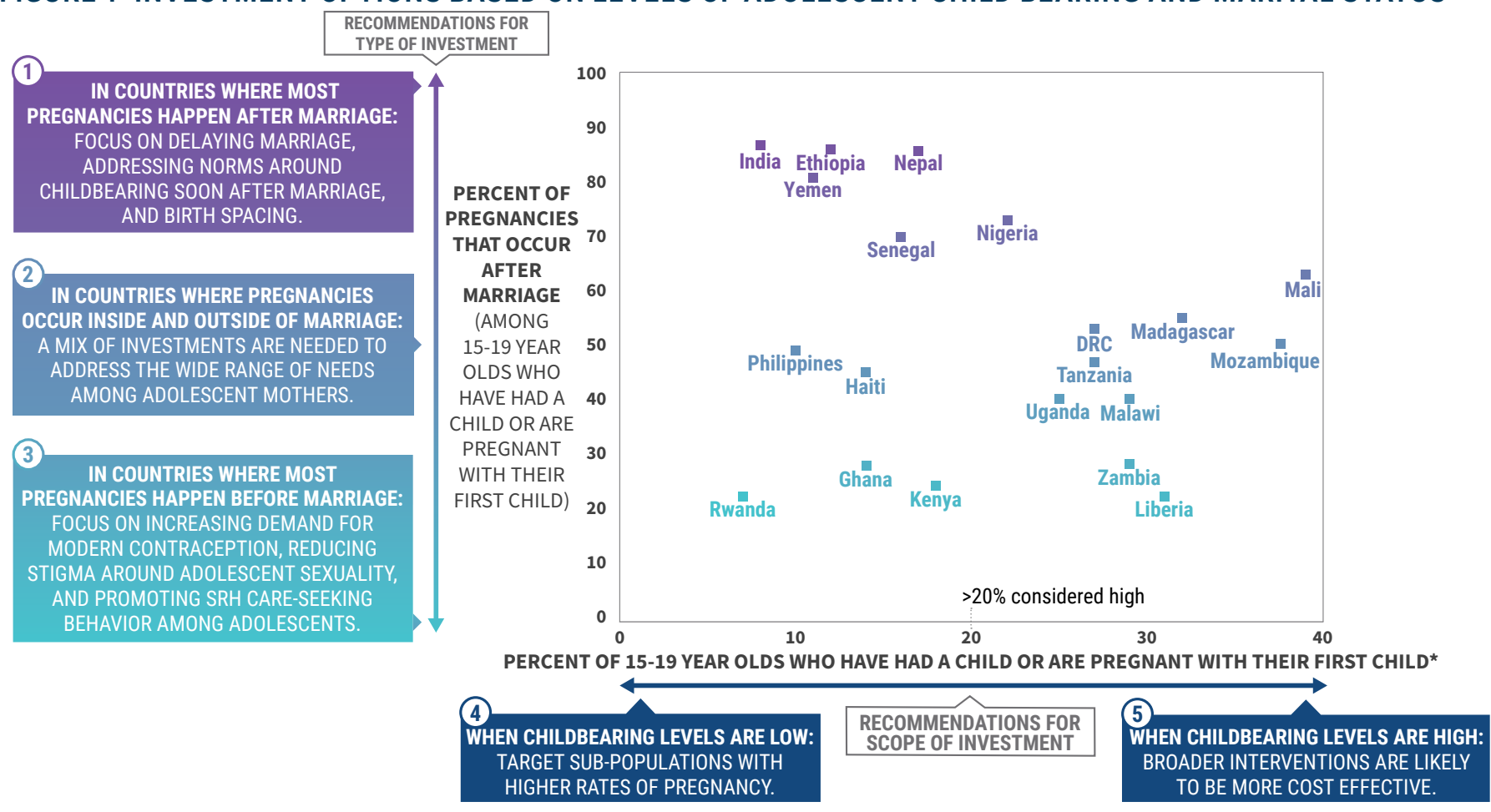

*If a girl has had more than one pregnancy, the timing of pregnancy (before or after marriage) is based on her first pregnancy

2 In countries where pregnancies occur inside and outside of marriage, e.g., Philippines, Haiti, DRC, Madagascar, a mix of SBC investments like those noted above are needed to address the wide range of $\mathrm{RH}$ needs among adolescent mothers. Investments should focus on addressing norms, increasing demand for modern contraceptives, and reducing stigma around adolescent sexuality. Supply side interventions to increase access to FP/RH services will also likely be needed.

3 In countries where most pregnancies happen before marriage, for example Rwanda, Ghana, Kenya, Zambia, and Liberia, SBC investments should focus on increasing demand for contraceptives among never married adolescents. SBC investments should also focus on community leaders, schools, and families to reduce stigma around adolescent sexuality, and promote supportive attitudes about RH care-seeking behavior among adolescents. Supply-side interventions that facilitate access to services and information for all adolescents should complement SBC. Avoid restricting access to services based on marital status, parity, or age. ${ }^{12}$

(4) When childbearing levels are low, for example Rwanda, India, and the Philippines, programming should target sub-populations with higher rates of pregnancy. Formative research and further sociodemographic segmentation can identify such sub-populations with the greatest need and identify key drivers of early pregnancy and childbearing.

(5) When childbearing levels are high, for example like in Madagascar, Liberia, Mali and Mozambique, SBC interventions that have wide reach across the adolescent population are likely to be more cost effective. Context specific research and evaluation on the diverse determinants of high rates of childbearing can inform promising opportunities for SBC and FP/RH investments.

\section{Methodology}

Each country's placement on the figure is based on two data points calculated from the most recent DHS survey. ${ }^{13}$ The proportion of 15-19 year olds who have begun childbearing includes those who have already had a birth and adolescents who were pregnant at the time of the survey. The second indicator is calculated among 15-19 year olds who have begun childbearing and is based on the first pregnancy experience. For each first adolescent pregnancy, the timing of the pregnancy is calculated relative to when the adolescent got married. The results depicted represent the overall proportion of pregnancies in the country that happened after marriage. The inverse of this result would therefore be the percentage of pregnancies that happened before marriage. This measure does not indicate the timing of the actual birth. In some cases, 15-19 year olds who got pregnant before marriage got married before giving birth. Combining these two indicators in the figure helps contextualize two important dimensions for adolescent pregnancy within a country. However, when considering investments within a country, additional data and information will be required to fully understand how to best target adolescent pregnancy. 


\section{References}

1. Guttmacher Institute. 2018. "Adding it up: costs and benefits of meeting the contraceptive needs of adolescents in developing regions," Factsheet. New York: Guttmacher Institute. https://www.guttmacher.org/fact-sheet/ adding-it-meeting-contraceptive-needs-of-adolescents

2. WHO defines an adolescent as any person between ages 10 and 19. Some data in the text and all data in the figure are specific to 15-19 year olds. In such cases, the data are marked accordingly.

3. USAID. "Adolescent sexual and reproductive ehealth program priorities." https://www.usaid. gov/what-we-do/global-health/family-planning/ adolescent-sexual-and-reproductive-health-programming

4. Sources: Blanc, AK, W. Winfrey, and J. Ross. 2013. "New findings for maternal mortality age patterns: aggregated results for 38 countries," PLOS ONE 8: e59864; Nove, A. et al. 2014. "Maternal mortality in adolescents compared with women of other ages: evidence from 144 countries," Lancet Global Health 2: e155e64; Ganchimeg, T. et al. 2014. "Pregnancy and childbirth outcomes among adolescent mothers: a World Health Organization multi-country study," BJOG 121(s1): 40e8; and Shah, I.H., and E. Åhman. 2012. "Unsafe abortion differentials in 2008 by age and developing country region: high burden among young women," Reprod Health Matters 20: 169e73.

5. Ganchimeg, T. et al. 2014. "Pregnancy and childbirth outcomes among adolescent mothers: a World Health Organization multi-country study," BJOG 121(S1): 40e8.

6. Thomas, A. 2012. "Policy solutions for preventing unplanned pregnancy," CCF Brief \#47. Washington, DC: Brookings Institute. Available from: https://www.brookings.edu/wp-content/ uploads/2016/06/03_unplanned_pregnancy_thomas.pdf

7. High-Impact Practices in Family Planning (HIPs). 2015. Adolescents: improving sexual and reproductive health of young people-a strategic planning guide. Washington, DC: USAID. Available from: https://www.fphighimpactpractices.org/guides/ improving-sexual-and-reproductive-health-of-young-people/

8. The Health Communication Capacity Collaborative HC3. 2014 Influencing the Sexual and Reproductive Health of Urban Youth through Social and Behavior Change Communication: a literature review. Baltimore: $\mathrm{JH}-\mathrm{CCP}$.

9. Svanemy, J. et al. 2015. "Creating an enabling environment for adolescent sexual and reproductive health: a framework and promising approaches," J Adolesc Health 56: S7e14.

10. Loaiza, E and M. Liang M. 2013. Adolescent Pregnancy: a review of the evidence. UNFPA: New York. Available from: https://www. unfpa.org/sites/default/files/pub-pdf/ADOLESCENT\%2OPREGNANCY_UNFPA.pdf

11. Sources: Svanemy, J. et al. 2015. "Creating an enabling environment for adolescent sexual and reproductive health: a framework and promising approaches," J Adolesc Health 56: S7e14; and Chandra-Mouli, V. et al. 2015. "Twenty years after International Conference on Population and Development: where are we with adolescent sexual and reproductive health and rights?," J Adolesc Health 56(1): s1-s6. Available at: http://ecommons.aku.edu/ eastafrica_fhs_mc_obstet_gynaecol/58

12. Sources: Denno, D.M., A. Hoopes, V. Chandra-Mouli. 2015. "Effective strategies to providing adolescent sexual and reproductive health services and to increasing demand and community support," J Adolesc Health 56: S22e41. Chandra-Mouli, V. et al. 2015. "Twenty years after International Conference on Population and Development: where are we with adolescent sexual and reproductive health and rights?," J Adolesc Health 56(1): s1-s6. Available at: http://ecommons.aku.edu/ eastafrica_fhs_mc_obstet_gynaecol/58

13. Sources-DHS data used in the graphic: Congo Democratic Republic 2013-14; Ethiopia 2016; Ghana 2014; Haiti 2012; India 2015-16; Kenya 2014; Liberia 2013; Madagascar 2008-09; Malawi 2015-16; Mali 2012 13; Mozambique 2011; Nepal 2016; Nigeria 2013; Philippines 2013; Rwanda 2014-15; Senegal 2015; Tanzania 2015-16; Uganda 2016; Yemen 2013; Zambia 2013-14

\section{Acknowledgments}

This programmatic research brief describes work led by Avenir Health under Breakthrough. The brief was developed in collaboration with Databoom, a consulting partner, and PRB a partner on Breakthrough RESEARCH.

Suggested citation: Breakthrough RESEARCH. 2019. "Prioritizing and targeting social behavior change investments to address adolescent pregnancy in USAID priority countries," Programm Research Brief. Washington DC: Population Council.

Front cover photo: @Lizzie Blenk, courtesy of the Population Council.

(C) 2019 The Population Council. All rights reserved.

\section{Email}

BreakthroughResearch@popcouncil.org

\section{Breakthrough RESEARCH | Population Council}

4301 Connecticut Ave., NW, Suite 280 | Washington, DC 20008

+12022379400 | breakthroughactionandresearch.org

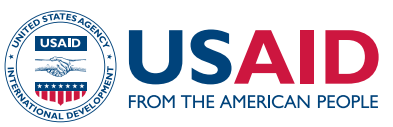

Breakthrough RESEARCH is made possible by the generous support of the American people through the United States Agency for International Development (USAID) under the terms of cooperative agreement no. AIDOAA-A-17-00018. The contents of this document are the sole responsibility of Breakthrough RESEARCH and Population Council and do not necessarily reflect the views of USAID or the United States Government.
POPULATION COUNCIL

Ideas. Evidence. Impact.

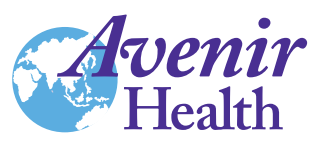

\section{databoom}

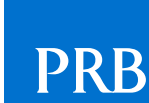

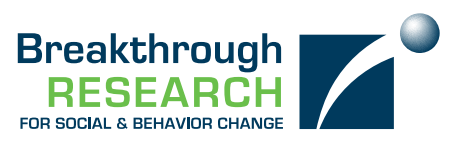

Our project turns evidence into action by providing thought provoking guidance to improve SBC policy and programming, with the goal of improving the cost-effectiveness of USAID's health and development strategies. Breakthrough RESEARCH catalyzes SBC by conducting state-of-the-art research and evaluation and promoting evidence-based solutions to improve health and development programs around the world. Breakthrough RESEARCH is a consortium led by the Population Council in partnership with Avenir Health, ideas42, Institute for Reproductive Health at Georgetown University, Population Reference Bureau, and Tulane University. 